\title{
The dynamics of commodity return comovements
}

\author{
Article \\ Published Version \\ Creative Commons: Attribution 4.0 (CC-BY) \\ Open Access
}

Prokopczuk, M., Wese Simen, C. and Wichmann, R. (2021)

The dynamics of commodity return comovements. Journal of Futures Markets. ISSN 1096-9934 doi:

https://doi.org/10.1002/fut.22222 Available at https://centaur.reading.ac.uk/98297/

It is advisable to refer to the publisher's version if you intend to cite from the work. See Guidance on citing.

To link to this article DOI: http://dx.doi.org/10.1002/fut.22222

Publisher: Wiley

All outputs in CentAUR are protected by Intellectual Property Rights law, including copyright law. Copyright and IPR is retained by the creators or other copyright holders. Terms and conditions for use of this material are defined in the End User Agreement.

\section{www.reading.ac.uk/centaur}

\section{CentAUR}

Central Archive at the University of Reading

Reading's research outputs online 


\title{
The dynamics of commodity return comovements
}

\author{
Marcel Prokopczuk ${ }^{1}$ (1) | Chardin Wese Simen ${ }^{2}$ () | Robert Wichmann ${ }^{3}$ (ㅇ)
}

\author{
${ }^{1}$ School of Economics and Management, \\ Leibniz University Hannover, Hannover, \\ Germany \\ ${ }^{2}$ Management School, University of \\ Liverpool, Liverpool, UK \\ ${ }^{3}$ ICMA Centre, Henley Business School, \\ University of Reading, Reading, UK

\section{Correspondence} \\ Robert Wichmann, ICMA Centre, Henley \\ Business School, University of Reading, \\ RG6 6BA Reading, UK. \\ Email: r.c.wichmann@pgr.icmacentre. \\ ac.uk
}

\begin{abstract}
We compare factor models with respect to their ability to explain commodity futures return comovements. A simple one-factor model based on the first principal component extracted from a panel of commodity returns outperforms a macroeconomic model, and explains most of the realized comovements. We find that intersectoral correlations display more time variations than intrasectoral correlations. Dissecting the evidence further, we find that comovements are driven by the variation of the factor as opposed to exposure to it. Our results cast doubt on the persistence of the effects of financialization and emphasize the importance of the dynamics of the factor variance.
\end{abstract}

\section{K E Y W O R D S}

commodity markets, comovement, factor model, financialization

\section{J E L C L A S S I F I C A T I O N}

G13, C38, F36, Q02

\section{1 | INTRODUCTION}

Commodity futures markets have undergone a massive transformation over the past decades. Surging demand from emerging countries, deregulation, and an increase of index investment by financial players have affected the correlations of commodity futures returns. ${ }^{1}$ Average pairwise correlations of commodity futures returns increased from $8 \%$ before 2004 to $23 \%$ after 2004 (Figure 1, top panel). This increase in correlations is also noticeable for return volatilities which rose from 13\% to 30\% during the same period (Figure 1, bottom panel). This finding is not discernible only for a specific commodity sector but rather for the entire cross-section (Figure 2$)^{2}{ }^{2}$

Our paper aims to shed light on the dynamics of these comovements. Is it the correlation (1) within sectors or (2) between different sectors that drives the time variation in comovements? How much of the comovements can be explained by factor models and thus what proportion is unexpected? Is this increase due to the time variation in (1) the factor sensitivities or (2) the factor covariances?

\footnotetext{
${ }^{1}$ In 2000, the Commodity Futures Modernization Act (CFMA) was enacted and changed the regulation of over-the-counter derivatives. As argued in Prokopczuk et al. (2017), this regulation lowered the barriers to entry of speculators in commodity markets. According to Tang and Xiong (2012), the value of index-related commodity investments increased from $\$ 15$ billion in 2003 to over $\$ 200$ billion in 2008. As of December 2017, Barclays reported global commodity assets under management have risen to $\$ 311$ billion. Moreover, Bhardwaj et al. (2015) show that the proportion of open interest from noncommercial traders has more than doubled between 1993 and 2014 as reported by the Commodity Futures Trading Commission (CFTC).

${ }^{2}$ The underlying data sample comprises daily returns for 27 commodity markets from April 1990 to December 2018. We follow Tang and Xiong (2012) and split the sample at the end of 2003.

This is an open access article under the terms of the Creative Commons Attribution License, which permits use, distribution and reproduction in any medium, provided the original work is properly cited.

(C) 2021 The Authors. The Journal of Futures Markets published by Wiley Periodicals LLC.
} 

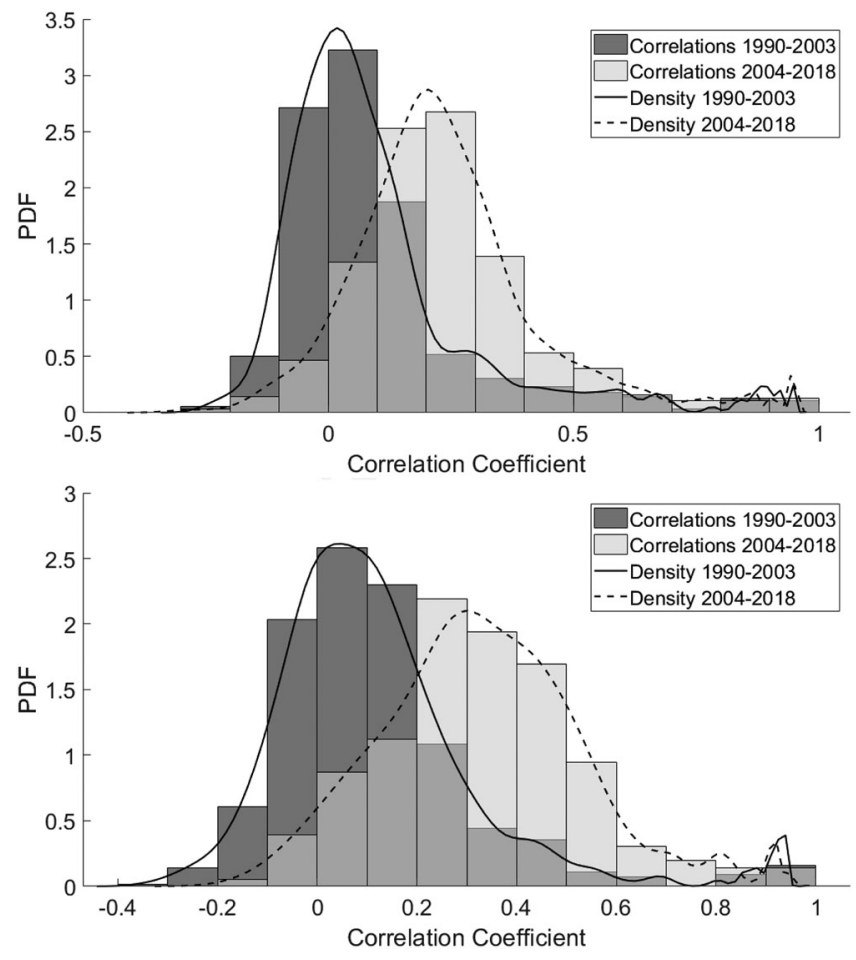

FI G URE 1 Distribution of pairwise correlation coefficients. This figure shows the distribution of the pairwise correlation coefficients for 27 commodity returns (return volatilities) in the upper (lower) panel. The sample period comprises monthly commodity returns and volatilities from April 1990 to December 2018. The dark shaded bars depict the histogram of correlation coefficients within the period from 1990 to 2003, while brightly shaded bars depict the histogram for the period from 2004 to 2018. The solid and dashed lines are density estimates using a normal kernel function for the distribution
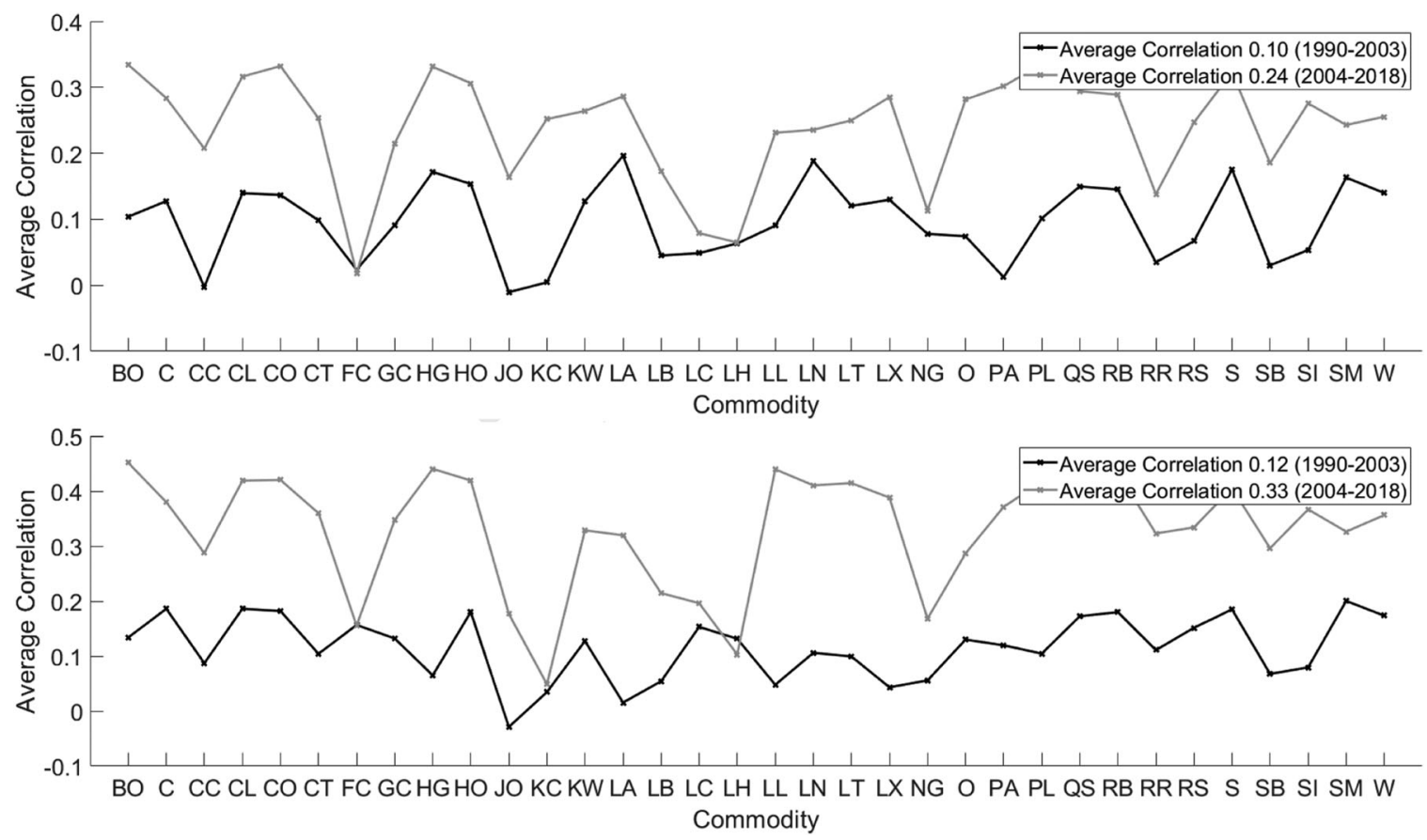

F I G URE 2 Average correlation coefficients. This figure shows the average pairwise correlation coefficient of each of 27 commodity futures returns with all other 26 commodity futures returns in the upper panel and the average pairwise correlation coefficient of each of 27 commodity futures return volatilities with all other 26 commodity futures return volatilities in the lower panel. The sample period comprises monthly commodity futures returns and volatilities estimated from daily data from April 1990 to December 2018. The black line shows the period from 1990 to 2003, while the gray line shows the period from 2004 to 2018. The average correlation rose from $9 \%$ to $22 \%$ for returns and from $12 \%$ to $33 \%$ for volatilities between the two periods. The horizontal axis lists the commodity ticker symbols, for details see Table A.1 of the online appendix 
The main results of our study are threefold. First, we find that a simple one-factor model can explain $96 \%$ of the realized comovements in commodity returns. Second, we document that the high comovements observed during and after financialization are mostly driven by comovements between different commodity sectors rather than within sectors. Third, the time variation in the factor variance as opposed to the time variation in factor exposure is the main contributor to the dynamics of comovements during this period.

We begin by comparing two empirical models for commodity futures returns: (1) a global one-factor model extracted from the panel of commodity returns (DelleChiaie et al., 2017) and (2) a macro factor model that extracts information from 184 macroeconomic variables (Le Pen \& Sévi, 2017). ${ }^{3}$ We compare the models' ability to fit the covariance structure of commodity returns and find that the model with one global factor outperforms the macro factor model.

Dissecting the comovement into the part driven by intrasectoral correlations and the part driven by intersectoral correlations, we find that while both parts have increased during and after financialization, it is the comovement between commodities of different sectors that drives the time variation in the total comovement. Next, we decompose the return comovements into a model-implied component and a surprise component. We find that the model-implied component accounts for virtually all of the realized comovements. Pushing the analysis further, we show that the variation in the model-implied component depends on (i) the variation in the factor sensitivity and (ii) the factor variance. By fixing one of the two parts to its time-series average, all variation is induced by the other part. A comparison of the results shows that while the model with fixed factor coefficient is still able to reproduce the main features of the comovement, the model with fixed factor variance shows completely different dynamics.

Our work relates to the literature on excess return comovements. Pindyck and Rotemberg (1990) regress commodity returns on six selected US macroeconomic variables. Their analysis is extended by Le Pen and Sévi (2017) who consider the information content of 184 macroeconomic variables related to the US and international markets. Filtering out the effects of these macro variables on commodity returns, both studies interpret the correlation of the filtered returns as evidence of excess comovement. We find that a simple one-factor model (Delle Chiaie et al., 2017) provides a better fit to the comovement of commodity returns, casting doubt on the excess comovement documented in the literature. Adhikari and Putnam (2020) use a copula approach to study the comovements of commodity markets and find that the excess comovement within sectors is stronger than across.

Our work also relates to the broader literature on the modeling of commodity return comovements. Several studies use GARCH-type models to directly model the correlation of returns (Berben \& Jansen, 2005; Deb et al., 1996; Ohashi \& Okimoto, 2016; Silvennoinen \& Thorp, 2013). Our approach is different. We use a factor model for commodity returns and explore its implications for comovements. Thus, our methodology enables us to derive the covariance as a product of beta and factor variance and assess their contribution to the model-implied comovements.

Our study also contributes to the growing literature on commonalities of return volatilities. Dahl et al. (2020) study volatility spillovers between oil and agricultural markets. Christoffersen et al. (2019) document that while the increase in return comovements of commodities has been temporary, volatility comovements have increased during the crisis and there is no evidence of a decline in the more recent period. Our results show that volatility comovements are in fact lower during the financialization period, and jump to a persistently higher regime after the financial crisis of 2008/2009. The increase in return comovements on the other hand is marked by a gradual increase starting before the financial crisis. Thus, it is important to draw a clear distinction between the effects of financialization and the financial crisis on commodity market comovements.

We contribute to the literature on the integration of commodity markets. ${ }^{4}$ Tang and Xiong (2012) show that the correlations of commodity futures returns have increased substantially and this effect is especially pronounced for commodities that are part of commodity indices. Cheng and Xiong (2014) discuss the impact of financial investors on commodity markets, arguing that they mitigate hedging pressure and improve risk sharing, but also induce shocks due to risk constraints and financial distress. Henderson et al. (2015) use a novel data set of commodity-linked notes to identify the relation between price movements and hedging trades. Our findings shed light on how financialization has affected commodity markets. By financialization, we mean the increase of institutional investors that follow momentum strategies (Bhardwaj et al., 2014), or invest in different generations of commodity indices, for example, including carry and momentum strategies. While it is undisputed that correlations between commodity markets have risen during financialization, the fact that the time variation of factor variance is the main contributor to the increase in return comovements, helps to explain the long-term effects of financialization.

${ }^{3}$ In a previous version of this paper we also considered the factor model of Bakshi et al. (2019). However, the global one-factor model provides a better description of commodity returns. We thank a referee for suggesting this analysis.

${ }^{4}$ We concentrate on the financial aspects, but acknowledge that there is also a large macroeconomic literature on this topic, which is summarized by Fattouh et al. (2013). 
Our work builds on the research of Bekaert et al. (2009) who analyze the impact of globalization on cross-country and cross-industry stock return comovements. In their seminal study, they find that while factor covariances exhibit substantial time variation in the short term, permanent trend changes in comovements are more likely to be induced by changes in betas. Similar to globalization, the financialization of commodity markets has often been argued to cause increased comovements in commodity markets. To investigate this claim, we build on the econometric framework of Bekaert et al. (2009). Our interest in this framework is motivated by three points. First, it starts with a model that can explain most of the comovement of returns. Second, it enables us to decompose the comovements into intra-sector as well as as intersector components. Third, the methodology can shed light on whether the changes in comovements stem from the dynamics of the factor sensitivity or instead the factor variability. Finally, we go a step further and leverage the detailed data set of trading positions of commercial and noncommercial players published by the CFTC. This data set enables us to study the impact of trading activity on the comovement measure. ${ }^{5}$

Our findings show that financialization has affected commodity futures returns in the short-term, but had limited effects on the long-term integration of commodity markets. Whether changes in factor sensitivity or factor variance drive the increased comovement is of fundamental importance as it calls for different reactions of regulators and practitioners. From a regulatory perspective, our findings question the view that a stricter regulation of financial traders in commodity markets will reduce comovements. ${ }^{6}$ From an asset and risk management perspective, our results show the importance of extracting information from a panel of commodity futures returns rather than macroeconomic factors to analyze correlation dynamics. Our results indicate that failing to model the dynamics of factor variance leads to erroneous risk assessment. For example, using the empirical distribution of the returns with fixed factor variance, results in an estimated 3\% decrease of value-at-risk $(\mathrm{VaR})$ within the period of financialization, while the realized or model-implied returns show that VaR has increased by $21 \%$.

The remainder of this paper is organized as follows. Section 2 describes the data and methodology. Section 3 introduces and compares the factor models. Section 4 dissects the commodity comovements. Section 5 discusses the implications of our findings. Section 6 documents several robustness checks, and Section 7 concludes.

\section{2 | DATA AND METHODOLOGY}

\subsection{Data}

We obtain daily commodity futures price and volume data from Bloomberg. ${ }^{7}$ The data covers 27 major commodity futures markets, divided into six sectors: Energy, Grains, Livestock, Oilseeds, Metals, and Softs as listed in Table A.1 of the online appendix. ${ }^{8}$ We gather financial data on Treasury rates, credit spreads, corporate bond yields, and stock volatility data from the Federal Reserve Bank of St. Louis (FRED) as listed in Panel A of Table A.2 of the online appendix. Furthermore, we collect the same 184 macroeconomic variables as Le Pen and Sévi (2017) from DataStream as listed in Panel B of Table A.2 of the online appendix. Our main analysis concentrates on the period from April 1990 to December 2018. ${ }^{9}$

To construct a continuous time series, we roll over the contract closest to maturity at the end of the month preceding the month before delivery. This approach is analogous to Szymanowska et al. (2014) and enables us to avoid illiquidity concerns once the contract is close to maturity. We roll over all nearbys at the same time, that is, if $t$ is a roll over date, for any $n$ the $(n+1)$ th nearby becomes the $n$th nearby. This has further implications on the computation of the return series, as on the day before a roll over day, we have to account for the fact, that the $(n+1)$ th nearby will be the $n$th nearby on the following day. By doing this, we guarantee that the computed return is realizable since it is based on the prices of the same contract (Singleton, 2014). For commodity market $i$ we can write the return on the $n$th nearby on day $t$ as

\footnotetext{
${ }^{5}$ We are grateful to a reviewer for suggesting this analysis.

${ }^{6}$ See also the literature on the "Masters Hypothesis" (Irwin \& Sanders, 2012), that tries to explain the links between index investments and commodity prices.

${ }^{7}$ Note that up to Section 3, we use the monthly frequency since the macro data is not measured at the daily frequency. We return to the daily frequency from Section 4 onwards. In unreported robustness checks, we confirm that our conclusions are independent of the sampling frequency.

${ }^{8}$ This choice of sectors is identical to Szymanowska et al. (2014) except for merging the materials with the softs sector because it only contains two commodities.

${ }^{9}$ One could extend the sample back to July 1959. Within this early period the composition of the sample changes drastically, when new commodities are introduced, affecting comovements. Hence, we concentrate on the later period, during which the composition of the sample is constant.
} 


$$
R_{i, t}^{(n)}:=\left\{\begin{array}{l}
\frac{P_{i, t}^{(n)}}{P_{i, t-1}^{(n+1)}}-1, \text { if } t-1 \text { is a roll over day } \\
\frac{P_{i, t}^{(n)}}{P_{i, t-1}^{(n)}}-1, \quad \text { otherwise, }
\end{array}\right.
$$

where $P_{i, t}^{(n)}$ is the price of the $n$th nearby on day $t$. Summary statistics for the first nearby returns of all commodities are provided in Table 1 and show common characteristics of commodity futures markets. Annualized mean returns differ strongly between commodities (e.g., 7.8\% for copper, but $-5.2 \%$ for corn) and within sectors (e.g., 13.9\% for gasoline, but $-9.0 \%$ for natural gas), and volatility ranges from $13.9 \%$ for live cattle to $44.8 \%$ for natural gas.

\section{2 | Methodology}

Having constructed the return series of commodity futures, we now aim to decompose the covariance of returns. Suppose that for a commodity the return on the first nearby emerges from its linear exposure to $K$ factors. For every commodity market $i$, we run the time-series regression:

TA B LE 1 Summary statistics bloomberg commodity futures returns

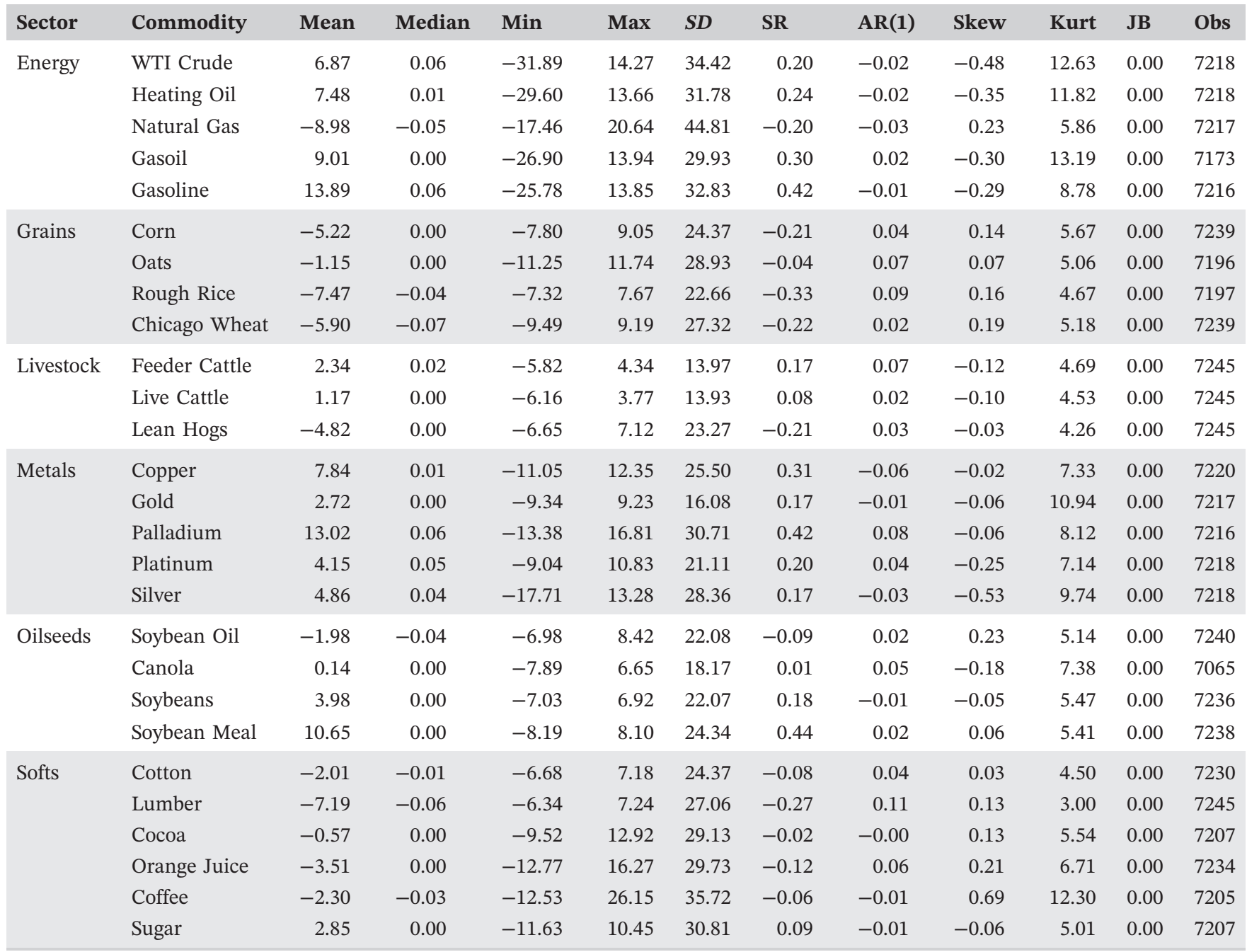

Note: This table reports summary statistics of daily commodity futures returns on 27 commodities obtained from Bloomberg for the period from April 1990 to December 2018. We report the mean (Mean), median (Median), minimum (Min), maximum (Max), standard deviation (SD), Sharpe ratio (SR), first order autocorrelation (AR(1)), skewness (Skew), kurtosis (Kurt), the $p$-value of a Jarque-Bera test (JB) and the number of observations (Obs). For ease of comparison with the literature, mean, standard deviation and Sharpe ratio are annualized and expressed in percentage points. 


$$
R_{i, t}=\alpha_{i}+F_{t} \beta_{i}+\epsilon_{i, t} \quad \forall t=1, \ldots T,
$$

where $R_{i, t}$ is the commodity futures return, $\alpha_{i}$ is the intercept, $F_{t}$ is the $1 \times K$ vector of factors, $\beta_{i}$ is the $K \times 1$ vector of slope coefficients and $\epsilon_{i, t}$ denotes the residual. The covariance between the two vectors of commodity futures returns $R_{i}$ and $R_{j}$ is then given by

$$
\underbrace{\operatorname{Cov}\left(R_{i}, R_{j}\right)}_{\text {Realized Covariance }}=\underbrace{\beta^{\prime} \cdot \Sigma_{F} \cdot \beta_{j}}_{\text {Model-Implied Covariance }}+\underbrace{\operatorname{Cov}\left(\epsilon_{i}, \epsilon_{j}\right),}_{\text {Residual Covariance }}
$$

where $\Sigma_{F}$ denotes the $K \times K$ covariance matrix of the factors and $\epsilon_{i}$ and $\epsilon_{j}$ denote the vectors of residuals for the respective commodity market. Equation (3) illustrates that we can always decompose the realized covariance into a model-implied component and a residual component. This identity is useful to evaluate how much of the realized comovement can be explained by the respective model.

\section{3 | MODEL SELECTION}

In this section, we introduce two factor models. The first model uses a single global commodity factor. The second model uses macroeconomic variables to explain commodity futures returns. After describing the estimation process of each model, we compare their ability to describe commodity market comovements.

\section{1 | Commodity factor model}

The first empirical model we consider is based on the work of Delle Chiaie et al. (2017) who find that a single global factor drives the bulk of commodity return fluctuations. Therefore, we extract the first principal component from the panel of commodity returns, $P C_{\text {global }}$, and set $F:=P C_{\text {global }}$ in Equation (2). The global factor explains $23.4 \%$ of the common variation of commodity returns.

Since all loadings are positive, the global factor can be interpreted as the return on a weighted long-only portfolio of all commodities. We use only one factor as this is the most parsimonious approach possible. ${ }^{10}$

\section{2 | Macro factor model}

The second model is based on the work of Pindyck and Rotemberg (1990) who argue that comovements between commodity markets are driven by common macroeconomic shocks. In their seminal study, they define excess comovement as any comovement that cannot be explained by variables such as inflation, industrial production, interest rates, and exchange rates. As resources for construction, energy supply, or the production of goods, commodities are strongly linked with global aggregate demand (Alquist et al., 2020). Therefore, the change in the commodity comovements should be linked to a macroeconomic shock. To validate this economic reasoning, it is necessary to capture all possible channels by including a large set of macro variables.

While Pindyck and Rotemberg (1990) use only six variables (industrial production, inflation, currency index, interest rates, money supply and stock returns), Le Pen and Sévi (2017) extend the variable set to 184 macro variables from emerging as well as developed countries. We follow the authors by using the same 184 variables and taking logarithms and/or first or second differences to obtain stationary variables. ${ }^{11}$ Subsequently, we reduce the dimensionality of the data set by using principal component analysis. In particular, we

\footnotetext{
${ }^{10}$ We thank an anonymous referee for this suggestion. It is, however, worth pointing out that recent works by Bakshi et al. (2019) and Boons and Prado (2019) propose three-factor models for commodity returns. In an earlier version of this paper, we considered such models. We find that the simple one-factor model discussed above provides a better fit to the covariance structure of futures returns.

${ }^{11}$ Panel B of Table A.2 in the Online Appendix provides a list of variables and transformations.
} 
use the first nine components as factors for the macro factor model, that is, we set $F=\left(P C_{1}, \ldots, P C_{9}\right)$ in Equation (2). ${ }^{12}$

\subsection{Estimation of factor sensitivities}

In the following, we will introduce three different ways to obtain a series of parameter estimates for the described models.

\subsection{1 | Constant beta}

Up to this point, we assumed the exposure of commodity returns to the pricing factors is constant, that is, $\beta_{i}(t)=\beta_{i}$ for every $t$. In practice, this means we use the full sample period to estimate the parameters of interest.

\subsection{2 | Re-estimated beta}

It is possible that the factor exposures change over time. The simplest way to introduce time variation is by re-estimating the models. We do this using a rolling window of the past 36 months, and obtain a monthly series of coefficients. ${ }^{13}$

\subsection{3 | Parametric beta}

Another approach is to model the time variation explicitly. We follow Bekaert et al. (2009) and use several financial variables to capture the dynamics of $\beta$. More formally, we model $\beta_{i}$ using $K_{M}$ factors as:

$$
\beta_{i}(t)=\gamma_{i}^{0}+M_{t} \gamma_{i}
$$

where $\beta_{i}(t)$ is the coefficient vector at time $t, \gamma_{i}^{0}$ is the intercept and $\gamma_{i}$ is the $K_{M} \times 1$ vector of sensitivities towards the financial variables in the $K \times K_{M}$ matrix $M_{t}$. Specifically, we use the following variables: the 3-month T-bill rate (US3M) to capture interest rates, the spread between 10-year and 3-month Treasury rates (TERM) as a measure for the term premium, the spread between Moody's Seasoned Baa and Aaa Corporate Bond Yield (DEF) to account for aggregate credit risk, the spread between 3-month LIBOR and Treasury rate (TED) as a measure of funding liquidity and the CBOE Volatility Index (VIX) as a measure for stock market volatility. This choice reflects the view that commodity futures traders also engage in financial markets and hence adjust their risk exposures according to financial conditions.

This approach requires only one estimation, because by extending the baseline regression in Equation (2) to include the $K \times K_{M}$ combinations of factors and financial variables, we only need to estimate

$$
R_{i, t}=\alpha_{i}+F_{t} \beta_{i}(t)+\epsilon_{i, t}=\alpha_{i}+F_{t}\left(\gamma_{i}^{0}+M_{t} \gamma_{i}\right)+\epsilon_{i, t}
$$

and compute the coefficients, $\beta_{i}(t)$, by plugging the estimated coefficients, $\gamma_{i}^{0}$ and $\gamma_{i}$, into Equation (4). Note that effectively the "Constant Beta" approach is nested within Equation (5), as setting $M_{t}=0$ results in $\beta_{i}(t)=\gamma_{i}^{0}$ for all $t$.

\subsection{Model comparison}

As we are interested in how comovements of commodity returns change over time, we will look at the decomposition from (3) in a rolling window manner. Let $\tau$ be a rolling window of 36 months, then the correlation of two commodity returns can be written as

\footnotetext{
${ }^{12}$ The first nine components jointly explain $34.4 \%$ of the total variation in all 184 dimensions. For a slightly smaller sample, Le Pen and Sévi (2017) find the first nine principal components to jointly explain $37 \%$ of the total variation.

${ }^{13}$ This choice of rolling window size ensures a sufficient number of observations for estimation, while keeping the window as small as possible. We also use smaller and larger window sizes in robustness checks.
} 


$$
\begin{aligned}
& \frac{\operatorname{Cov}_{\tau}\left(R_{i}, R_{j}\right)}{\sqrt{\operatorname{Var} r_{\tau}\left(R_{i}\right) \operatorname{Var}\left(R_{j}\right)}} \stackrel{(3)}{=} \frac{\beta^{\prime} \cdot \Sigma_{F, \tau} \cdot \beta_{j}}{\sqrt{\operatorname{Var}\left(r_{\tau}\right) \operatorname{Var}\left(R_{\tau}\right)}}+\frac{\operatorname{Cov}_{\tau}\left(\epsilon_{i}, \epsilon_{j}\right)}{\sqrt{\operatorname{Var} r_{\tau}\left(R_{i}\right) \operatorname{Var}\left(r_{\tau}\right)}}, \\
& \rho_{i j}^{\text {real }}(\tau)=\rho_{i j}^{\text {model }}(\tau)+\rho_{i j}^{\text {resid }}(\tau)
\end{aligned}
$$

where $R_{i}$ and $R_{j}$ are the returns on the respective commodities $i$ and $j, \beta_{i}$ and $\beta_{j}$ are the respective slope coefficients, $\Sigma_{F, \tau}$ is the covariance of pricing factors within the window, and $\epsilon_{i}$ and $\epsilon_{j}$ are the respective error terms. As for the covariance in (3), the correlation decomposes into a realized, model-implied, and residual part.

Since correlations are conditional on volatilities, heteroskedasticity can bias the conditional correlation coefficients. Therefore, we follow Le Pen and Sévi (2017) and adjust the correlation coefficient as proposed by Forbes and Rigobon (2002). We denote the heteroskedasticity-adjusted correlation coefficient as

$$
\rho_{i j}^{*}=\frac{\rho_{i j}}{\sqrt{1+\delta_{i}\left(1-\rho_{i j}^{2}\right)}} \quad \text { with } \quad \delta_{i}=\frac{\operatorname{Var}_{\text {short }}\left(R_{i}\right)}{\operatorname{Var}_{\text {long }}\left(R_{i}\right)}-1 \text {, }
$$

where $\rho_{i j}$ is the nonadjusted correlation coefficient, $\operatorname{Var}$ short $\left(R_{i}\right)$ is the variance of $R_{i}$ over half the observations compared to $\operatorname{Var}_{\text {long }}\left(R_{i}\right)$. In our baseline model this refers to 36 months for $\operatorname{Var}_{\text {long }}\left(R_{i}\right)$ and 18 months for $\operatorname{Var}_{\text {short }}\left(R_{i}\right)$. Applying this adjustment to the left and right-hand side of (6), we obtain the heteroskedasticity-adjusted correlations, $\rho_{i j}^{\text {real }}(\tau)^{*}, \rho_{i j}^{\text {model }}(\tau)^{*}$, and $\rho_{i j}^{\text {resid }}(\tau)^{*}$ for the realized, model-implied, and residual part, respectively.

Now, we can define the comovement measure (CM) as the weighted average of the off-diagonal correlation coefficients. More precisely, we define

$$
\mathrm{CM}^{\text {real }}(\tau):=\sum_{i, j, i \neq j} w_{i j} \rho_{i j}^{\text {real }}(\tau)^{*} \quad \text { and } \quad \operatorname{CM}^{\text {model }}(\tau)=\sum_{i, j, i \neq j} w_{i j} \rho_{i j}^{\text {model }}(\tau)^{*},
$$

where $w_{i j}$ are weights such that $\sum_{i, j, i \neq j} w_{i j}=1 .{ }^{14}$ Following from (3), the realized comovement, $\mathrm{CM}^{\text {real }}$, can be decomposed into a model-implied and a residual part.

To assess the performance of the different models, we compute the mean absolute error (MAE) and the root mean squared error (RMSE) based on the realized and model-implied comovement measures, that is,

$$
\begin{aligned}
\text { MAE } & =\frac{1}{N} \sum_{n=1}^{N}\left|\mathrm{CM}^{\text {real }}\left(\tau_{n}\right)-\mathrm{CM}^{\text {model }}\left(\tau_{n}\right)\right| \\
\operatorname{RMSE} & =\frac{1}{N} \sum_{n=1}^{N}\left(\operatorname{CM}^{\text {real }}\left(\tau_{n}\right)-\mathrm{CM}^{\text {model }}\left(\tau_{n}\right)\right)^{2},
\end{aligned}
$$

where $N$ is the number of comovement observations. Bekaert et al. (2009) use these measures for equity comovement as well as Anderson (2017) for credit default swaps.

Before we compare the models with respect to the comovements, we take a look at the results of the timeseries regressions for the commodity factor model in Table 2 and the macro factor model in Table 3. The reported coefficients show the coefficients for the whole sample period, that is, the "Constant Beta" approach. Looking at the $R^{2}$, we find that the commodity factor model can explain $19.7 \%$ of the return variation over all commodities on average, while the macro factor model can only explain 9.9\%. Aggregating the commodities into sectors also shows that the commodity factor model performs reasonably well in all sectors apart from livestock. The macro factor model however, can only explain more than $10 \%$ of the variation for energy and metal commodities, which is in line with expectations as energy and metal markets are more closely related to economic conditions.

These preliminary results are clearly in favor of the global commodity factor model, but they are only informative about the model's ability to fit each single commodities variation in the time series. For the comovement of commodity markets instead, the model needs to account for the connections between different commodity markets, which cannot be inferred from time-series regressions that are estimated separately for each commodity market.

\footnotetext{
${ }^{14}$ Note that we sum over all nondiagonal elements instead of only the above-diagonal part because the transformation in Equation (7) is not symmetric. The weights are calculated as the average market value of traded contracts over the rolling window $\tau$. The necessary multipliers to obtain the value of a contract are listed in Table A.1 of the online appendix.
} 
TABLE 2 Regression results: Commodity factor model

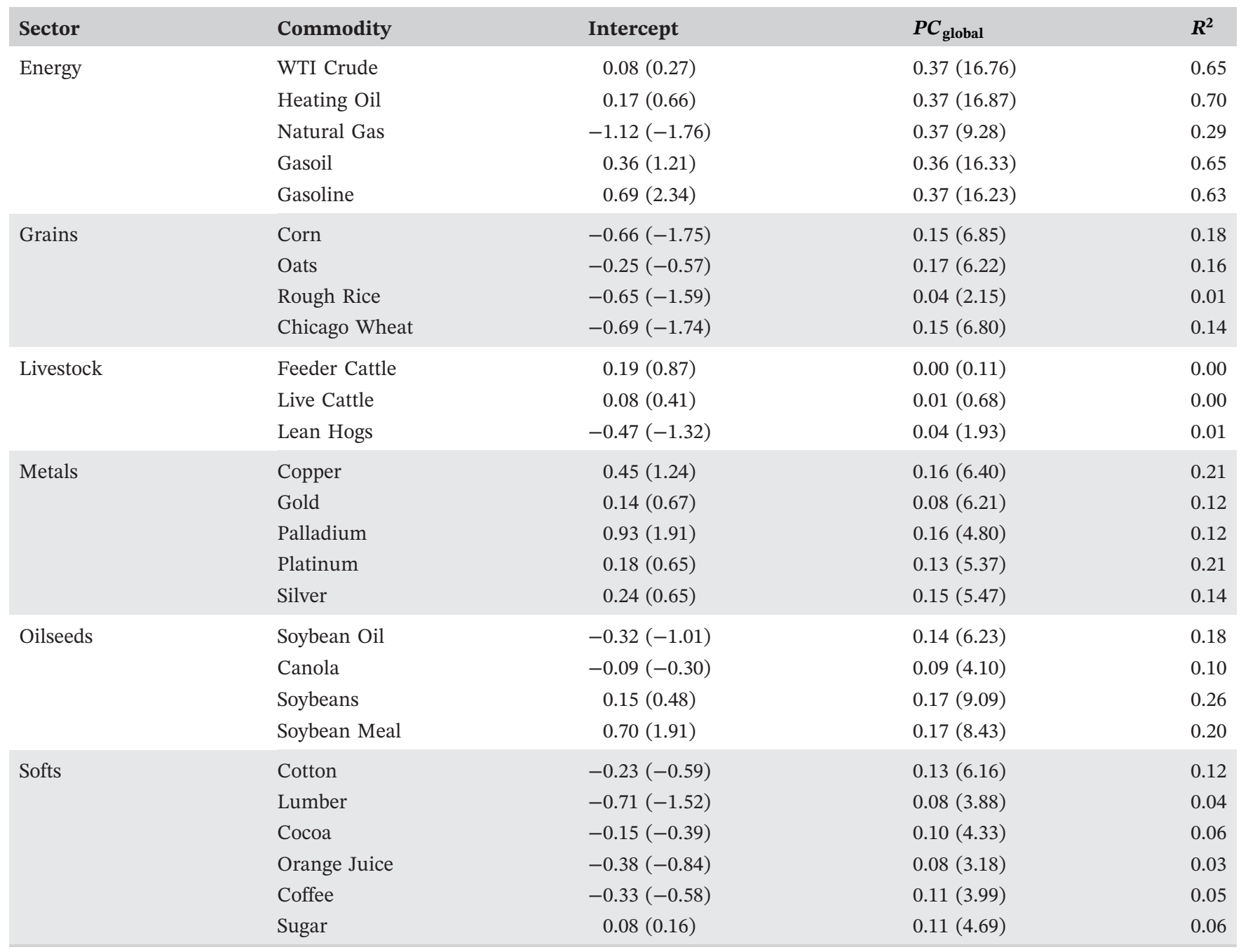

Note: This table reports the time series regression results of commodity futures returns on a constant and the first principal component extracted from a panel of 27 commodity returns. Standard errors are corrected according to Newey and West (1987) with two lags and respective $t$-statistics are reported in parenthesis. $R^{2}$ represents the coefficient of determination. Returns are in percentage points.

Table 4 reports the MAE and RMSE for both models and all three estimation methods, constant, parametric, and re-estimated beta. The conclusions conveyed by both panels of Table 4 are twofold.

First, for all three estimation methods and both performance measures, the global commodity factor model outperforms the macro factor model by a large margin. For the "Re-estimated beta" approach the MAE is only 0.0302 for the global commodity factor model compared to 0.1237 for the macro factor model. Independent of the measure and estimation technique, the error is always at least twice as large for the macro factor model.

Second, the results are strongly supportive of the model with re-estimated betas. While the introduction of parametric betas in general reduces the RMSE by only $4 \%$ from 0.0815 to 0.0780 for the global commodity factor model, reestimating the parameters reduces the error by $56 \%$ from 0.0780 to 0.0345 . These results also hold for the MAE and for the macro factor model.

Concluding this section, the global commodity factor model with re-estimated coefficients is the best model to fit the comovement structure of commodity futures returns and will thus be the benchmark for the dissection of commodity comovements in the following section. ${ }^{15}$ 
TABLE 3 Regression results: For macro factor model

\begin{tabular}{|c|c|c|c|c|c|c|}
\hline Sector & Commodity & Intercept & $\mathrm{PC}_{1}$ & $\mathrm{PC}_{2}$ & $\mathrm{PC}_{3}$ & $R^{2}$ \\
\hline \multirow{3}{*}{ Energy } & Heating Oil & $0.62(1.53)$ & $0.74(5.83)$ & $-0.61(-3.98)$ & $0.03(0.15)$ & 0.21 \\
\hline & Gasoil & $0.79(1.91)$ & $0.74(5.83)$ & $-0.67(-4.45)$ & $-0.06(-0.29)$ & 0.23 \\
\hline & Gasoline & $1.12(2.62)$ & $0.70(4.74)$ & $-0.58(-3.90)$ & $0.01(0.03)$ & 0.21 \\
\hline \multirow{3}{*}{ Grains } & Oats & $-0.09(-0.21)$ & $0.09(0.60)$ & $-0.24(-1.57)$ & $0.40(2.42)$ & 0.05 \\
\hline & Rough Rice & $-0.58(-1.45)$ & $0.20(2.16)$ & $-0.15(-1.36)$ & $0.11(0.78)$ & 0.05 \\
\hline & Chicago Wheat & $-0.52(-1.32)$ & $-0.02(-0.16)$ & $-0.13(-1.28)$ & $0.47(3.12)$ & 0.06 \\
\hline \multirow[t]{2}{*}{ Livestock } & Feeder Cattle & $0.20(0.92)$ & $0.11(1.78)$ & $-0.16(-2.25)$ & $0.11(1.25)$ & 0.04 \\
\hline & Live Cattle & $0.09(0.45)$ & $0.09(1.63)$ & $-0.17(-2.80)$ & $0.14(1.62)$ & 0.05 \\
\hline \multirow{3}{*}{ Metals } & Palladium & $1.08(2.27)$ & $0.21(1.38)$ & $-0.37(-2.01)$ & $0.85(3.78)$ & 0.09 \\
\hline & Platinum & $0.30(1.04)$ & $0.06(0.46)$ & $-0.33(-2.49)$ & $0.37(2.49)$ & 0.17 \\
\hline & Silver & $0.36(0.98)$ & $-0.02(-0.19)$ & $-0.15(-1.20)$ & $0.35(2.08)$ & 0.12 \\
\hline \multirow[t]{4}{*}{ Oilseeds } & Soybean Oil & $-0.17(-0.53)$ & $0.20(2.11)$ & $-0.24(-2.41)$ & $0.36(2.79)$ & 0.12 \\
\hline & Canola & $0.04(0.12)$ & $0.08(0.95)$ & $-0.11(-1.18)$ & $0.11(0.94)$ & 0.03 \\
\hline & Soybeans & $0.34(0.99)$ & $0.08(0.94)$ & $-0.16(-1.51)$ & $0.34(2.65)$ & 0.09 \\
\hline & Soybean Meal & $0.87(2.20)$ & $0.02(0.14)$ & $-0.11(-0.85)$ & $0.26(1.84)$ & 0.05 \\
\hline \multirow[t]{2}{*}{ Softs } & Cotton & $-0.17(-0.43)$ & $0.14(1.22)$ & $-0.30(-2.53)$ & $0.52(3.14)$ & 0.08 \\
\hline & Lumber & $-0.58(-1.33)$ & $0.13(1.10)$ & $-0.13(-0.97)$ & $0.51(3.01)$ & 0.08 \\
\hline
\end{tabular}

Note: This table reports the time series regression results of commodity futures returns on the first nine principal components extracted from a set of 184 macro variables following Le Pen and Sévi (2017). Standard errors are corrected according to Newey and West (1987) with two lags and respective $t$-statistics are reported in parenthesis. $R^{2}$ represents the coefficient of determination. Returns are in percentage points. Results for the fourth to ninth PC are omitted to keep the presentation manageable.

\section{4 | DISSECTING COMMODITY COMOVEMENTS}

This section introduces two ways of decomposing the proposed commodity comovement measure to obtain insights over the drivers of the time variation in commodity comovements. Further, we look at differences between return and volatility comovements in commodity markets. Following the previous section, we use the best model and estimation method to fit the commodity return comovements, that is, the one-factor model with re-estimated betas. While restricted to the monthly frequency for the model comparison, we can now use the daily frequency. ${ }^{16}$

\section{1 | Intra versus intersectoral return comovements}

We can decompose the comovement measure into comovements within the same sector and between different sectors. This is interesting as these aspects indicate different levels of market integration. A change in intrasectoral

\footnotetext{
${ }^{16}$ Robustness checks show that the commodity factor model performs even better in matching the comovement at the daily frequency than at the monthly frequency.
} 
TABLE 4 Comparison of commodity and macro factor model

\begin{tabular}{lll} 
Estimation method & Commodity factor model & Macro factor model \\
Panel A: Mean absolute error (MAE) & & 0.1654 \\
Constant beta & 0.0715 & 0.1423 \\
Parametric beta & 0.0674 & 0.1237 \\
Re-estimated beta & 0.0302 & 0.1865 \\
Panel B: Root mean squared error (RMSE) & & 0.1614 \\
Constant beta & 0.0815 & 0.1355 \\
Parametric beta & 0.0780 & 0.0345 \\
Re-estimated beta & & \\
\hline
\end{tabular}

Note: This table reports the mean absolute error (Panel A) and the root mean squared error (Panel B) associated with model (name in column). The commodity factor model is based on the first principal component extracted from the panel of 27 commodity returns. The macro factor model is based on the first nine principal components of a set of 184 macro variables following Le Pen and Sévi (2017). In Rows "Constant beta," the respective models are estimated once for the whole sample period. In Rows "Parametric beta," the coefficients are parametrized using the 3-month US LIBOR rate, the term spread between 10-year and 3-months US Treasury bill, the default spread between Moody's BAA and AAA Corporate Bonds Indices, the TED-spread between 3-month LIBOR and the Treasury rate, and the CBOE Volatility Index. In Rows "Re-estimated Beta," the coefficients are re-estimated for each rolling window.

comovements is more likely caused by sector specific channels, for example, the shale oil and gas boom for energy markets or weather conditions for agricultural markets. Intersectoral comovements, however, indicate a more general form of market integration as they are more likely caused by financial interconnectedness following the financialization.

To disentangle these effects, we partition the realized comovement into those correlation coefficients of commodities within the same sector and those of different sectors and obtain two disjoint parts,

$$
\mathrm{CM}^{\text {real }}(\tau)=\sum_{i, j, i \neq j} w_{i j} \rho_{i j}^{\text {real }}(\tau)^{*}=\underbrace{\sum_{\substack{i, j, i \neq j, S_{i}=S_{j}}} w_{i j} \rho_{i j}^{\text {real }}(\tau)^{*}}_{\text {Intrasectoral Component }}+\underbrace{\sum_{\substack{i, j, i \neq j, S_{i} \neq S_{j}}} w_{i j} \rho_{i j}^{\text {real }}(\tau)^{*}}_{\text {Intersectoral Component }},
$$

where $S_{i}$ and $S_{j}$ denote the commodity sector of commodity $i$ and $j$, such that, if $i$ and $j$ are in the same sector, $S_{i}=S_{j}$, while if they are in different sectors $S_{i} \neq S_{j}$.

Of course, the decomposition in (11) does not take into account the number of weighted correlation pairs in the disjoint parts. In our sample of 27 commodities covering 6 sectors, there are 351 different commodity market correlations pairs. From those 351 pairs, 50 are intrasectoral pairs and 301 are intersectoral pairs, that is, the intersectoral part consists of more than six times the number of correlation pairs that the intrasectoral part comprises. However, intrasectoral correlations are higher on average since commodities of the same sector are closer related to each other. To adjust for this imbalance, we scale both sums accordingly and obtain the intersectoral and intrasectoral comovement measures,

$$
\mathrm{CM}^{\text {intra }}(\tau)=\frac{1}{W_{\text {intra }}} \sum_{\substack{i, j, i \neq j, S_{i}=S_{j}}} w_{i j} \rho_{i j}^{\text {real }}(\tau)^{*} \quad \text { and } \quad \operatorname{CM}^{\text {inter }}(\tau)=\frac{1}{W_{\text {inter }}} \sum_{\substack{i, j, i \neq j, S_{i} \neq S_{j}}} w_{i j} \rho_{i j}^{\text {real }}(\tau)^{*},
$$

where $W_{\text {intra }}$ and $W_{\text {inter }}$ are scalars such that $\sum_{\substack{i, j, i=j, S_{i} \neq S_{j}}} w_{i j}=W_{\text {intra }}$ and $W_{\text {inter }}=1-W_{\text {intra }}$.

We split the sample into three subperiods before, during, and after financialization. The prefinancialization period lasts until December 2000, when the CFMA was enacted, allowing investors to directly trade in commodity derivatives (Prokopczuk et al., 2017). The increase of index investment into commodities during the first decade of the 21st century culminated in the boom and bust of commodity prices in 2008 (Singleton, 2014). We follow Delle Chiaie et al. (2017) and Alquist et al. (2020) by ending the financialization period in July 2008. This sample split also ensures three periods of roughly equal size. ${ }^{17}$

\footnotetext{
${ }^{17}$ In an earlier version of this paper, we divided the sample only once in December 2004 following Bhardwaj et al. (2015) and Main et al. (2018). Further, we used an alternative sample split including the financial crisis into the financialization period, which does not affect our results.
} 
The results of the above decomposition are presented in Table 5. Panel A of Table 5 confirms that comovements have significantly increased during the financialization period and remain on a higher level afterwards. The realized comovement more than doubled from 0.155 before to 0.329 after financialization $\left(t-\right.$ stat $\left._{\Delta}=16.88\right)$. This increase is matched in both the intrasectoral as well as intersectoral comovements but is relatively stronger for intersectoral comovements, which increased from 0.097 to 0.249 , while intrasectoral comovements increased from a much higher level of 0.644 to 0.671 . All changes are significant at the $1 \%$ level.

Panels B and C of Table 5 report the $S D$ of the comovement measures and their correlation with the realized comovement for the different periods. The volatility of comovement increases throughout the sample period. However, the volatility of the intrasectoral comovement has decreased after financialization. The intersectoral comovement shows the same pattern as the realized comovement with a strong and steady increase of volatility. Together with the high correlation between intersectoral and realized comovements of 0.960 over the whole sample, these results show that the time variation in comovements is driven by intersectoral comovements rather than intrasectoral comovements during and after financialization.

Figure 3 shows the time series of comovements and the decomposition into the intra- and inter-sectoral parts, confirming the discussed observations. Both, intra- and inter-sectoral comovements have contributed to the long-term increase in comovements during financialization, but the short-term time variation leading to a peak of comovement shortly after the crisis and a decrease in the most recent period is driven by the intersectoral comovements.

\section{2 | Factor sensitivities versus factor covariances}

Within the commodity factor model, the time variation of comovements has two potential sources, the fluctuations in factor sensitivity and the fluctuation in factor variance. We follow Bekaert et al. (2009) and set one of the two channels to its time-series average, so that all time variation is induced by the other part. We denote the respective correlations as

$$
\rho_{i j}^{\text {fixed } \beta}(\tau)=\frac{\overline{\beta_{i}}{ }^{\prime} \Sigma_{F, \tau} \overline{\beta_{j}}}{\sqrt{\operatorname{Var}_{\tau}\left(R_{i}\right) \operatorname{Var}_{\tau}\left(R_{j}\right)}} \quad \text { and } \quad \rho_{i j}^{\text {fixed } \Sigma}(\tau)=\frac{\beta^{\prime} \overline{\Sigma_{F}} \beta_{j \tau}}{\sqrt{\operatorname{Var}_{\tau}\left(R_{i}\right) \operatorname{Var}_{\tau}\left(R_{j}\right)}}
$$

where $\overline{\Sigma_{F}}$ is the time-series average of factor covariances and $\overline{\beta_{i}}$ is the time-series average of factor sensitivities for asset $i{ }^{18}$ We denote the heteroskedasticity-adjusted version as $\rho_{i j}^{\text {fixed } \beta}(\tau)^{*}$ and $\rho_{i j}^{\text {fixed } \Sigma}(\tau)^{*}$, respectively, and obtain the comovement measure with fixed factor exposures, $C M^{\text {fixed } \beta}$, and the comovement measure with fixed factor covariances, $C M^{\text {fixed } \Sigma}$, as

$$
C M^{\mathrm{fixed} \beta}(\tau)=\sum_{i, j, i \neq j} w_{i j} \rho_{i j}^{\mathrm{fixed} \beta}(\tau)^{*} \quad \text { and } \quad C M^{\mathrm{fixed} \Sigma}(\tau)=\sum_{i, j, i \neq j} w_{i j} \rho_{i j}^{\mathrm{fixed} \Sigma}(\tau)^{*}
$$

Table 6 reports the mean, $S D$, and correlation of the realized and model-implied comovement, as well as the comovements with fixed factor exposures and with fixed factor variances. The summary statistics for the model-implied comovement confirm that we are able to capture the increase on average comovement and volatility of comovement with the simple one-factor model also at the daily frequency. For the whole sample and all subsamples, the modelimplied comovement and the realized comovement measure have a correlation close to 1 .

With fixed factor sensitivity, the comovement measure $C M^{\text {fixed } \beta}$ is still closely related to the realized and modelimplied comovements. It also shows an increasing pattern for the average comovement as well as for the volatility of comovement. The correlation with the realized comovement exceeds 0.96 for the financialization and postfinancialization period, indicating that we capture the time variation in comovement for this period.

Fixing the factor variance however, leads to a very different picture. Panel A of Table 6 shows that, with fixed factor variance, the level of comovement is decreasing throughout the sample, contrary to what we observe during financialization. The volatility of the comovement measure $C M^{\text {fixed } \Sigma}$ is only slightly increasing and the correlation with the realized comovement over the whole sample is -0.384 , with 0.076 before, 0.799 during, and -0.379 after the financialization.

Finally, the graphs in Figure 4 confirm and illustrate these results. The time series of comovements is mainly driven by changes in the factor variance instead of changes in the sensitivity of the commodities towards the factor. While

\footnotetext{
${ }^{18}$ Since we use a single factor model, the covariance matrix is a scalar. Therefore, we will refer to it as the factor variance from hereafter.
} 
TA B L E 5 Intra- versus intersectoral commodity comovements

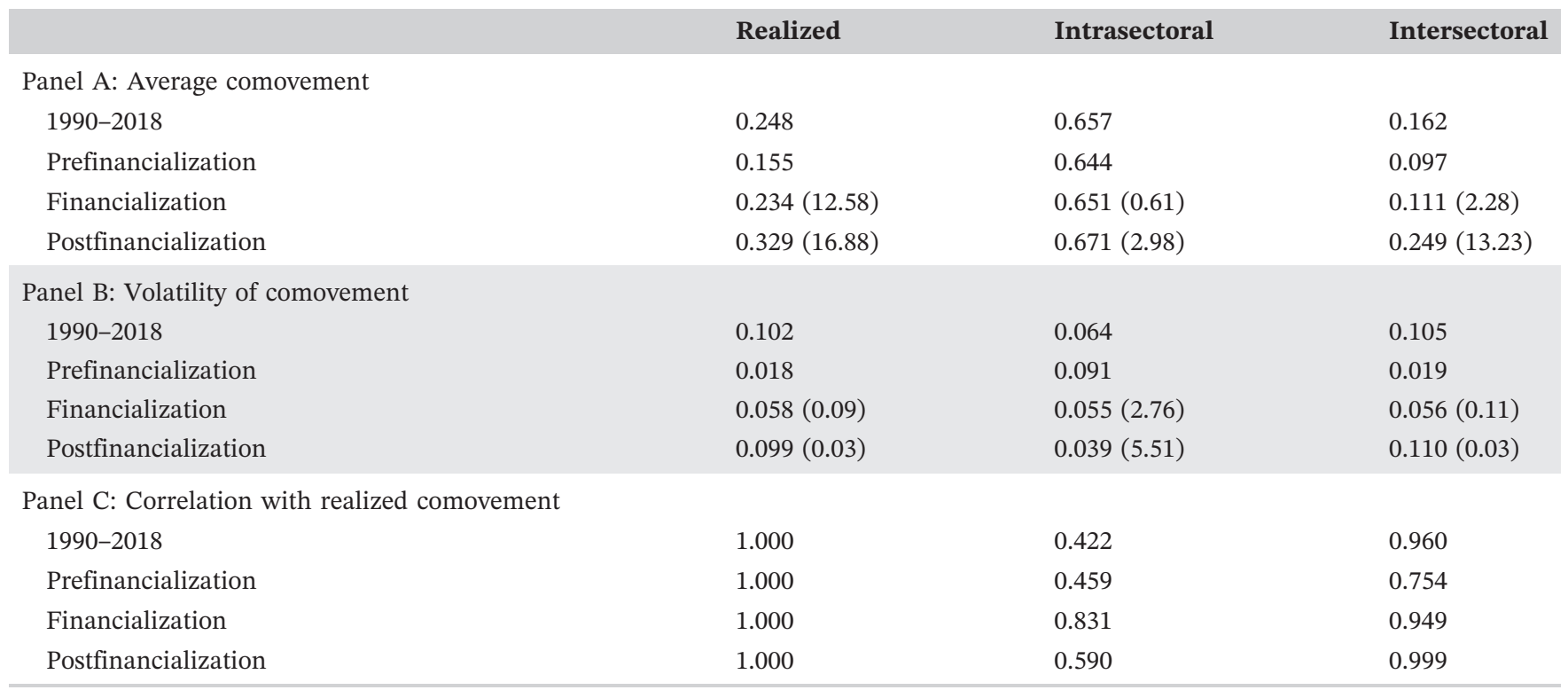

Note: This table reports the summary statistics of the commodity return comovement measure for the commodity factor model based on the first principal component extracted from the panel of 27 commodity returns. Panel A reports the average comovement, Panel B the $S D$ of the comovement and Panel C the correlation of the comovement with the realized comovement. The first column reports the realized comovement, $C M^{\text {real }}$, the second column reports the intrasectoral comovement, $C M^{\text {intra }}$, and the third column reports the intersectoral comovement $C M^{\text {inter }}$. Statistics for a two-sample $t$-test ( $F$-test) between the prefinancialization period and the financialization or postfinancialization period are reported in parenthesis in Panel A (Panel B).

F I G U RE 3 Intersectoral and intrasectoral commodity return comovements. This figure shows the realized commodity return comovement measure, $C M^{\text {real }}$, the intersectoral comovement measure, $C M^{\text {inter }}$ and the intrasectoral comovement measure, $C M^{\text {intra }}$, as defined in Equation (12). Comovements are measured as the weighted average of all correlation pairs, and then dissected into those pairs from the same (intrasectoral) and different (intersectoral) sectors. The correlations are adjusted for heteroskedasticity (Forbes \& Rigobon, 2002) and computed over a rolling window of 36 months. The light red shaded area marks the period of financialization from December 2000 to July 2008, dark shaded areas mark NBER recessions

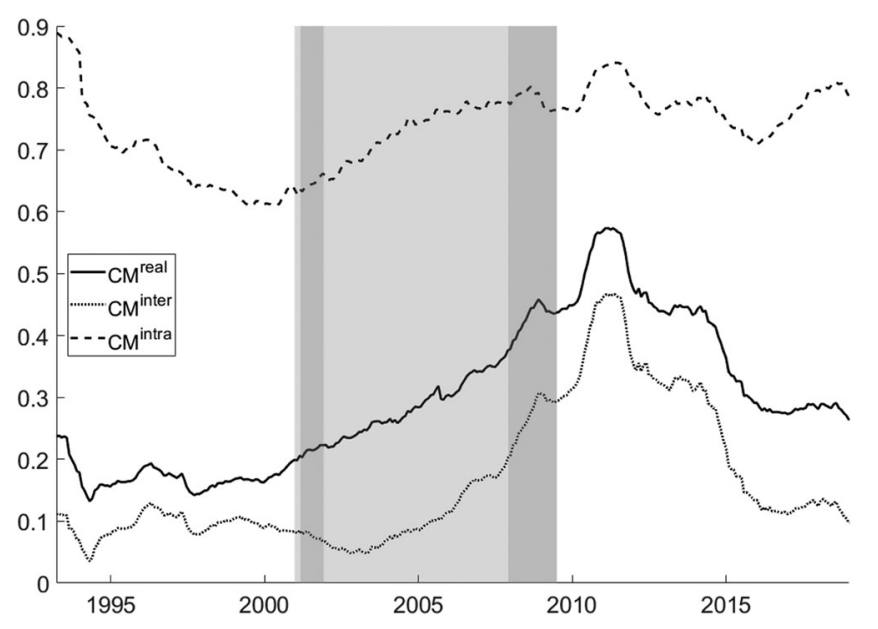

factor variances exhibit substantial time variation in the short term, trend changes in comovements are more likely to come from changes in betas (Bekaert et al., 2009). Therefore, the evidence suggests that financialization has affected the factor variance rather than the sensitivity of commodity returns to the factor.

\section{3 | Return versus volatility comovements}

The previous results are also interesting with respect to the study of Christoffersen et al. (2019), who argue that commodity return correlations have returned to their precrisis level, but find a persistently higher degree of volatility correlations after the financialization. To address this point, we also look at comovements between commodity return volatilities, by applying the same framework as before to return volatilities as the underlying variables. Let $V_{i}$ be the series of monthly return volatilities for a commodity market $i$ and 
TABLE 6 Commodity comovements with fixed betas and factor covariances

\begin{tabular}{|c|c|c|c|c|}
\hline & Realized & Model & Fixed $\beta$ & Fixed $\Sigma$ \\
\hline \multicolumn{5}{|c|}{ Panel A: Average comovement } \\
\hline 1990-2018 & 0.248 & 0.253 & 0.255 & 0.296 \\
\hline Financialization & $0.234(12.58)$ & $0.238(12.02)$ & $0.236(13.00)$ & $0.249(-11.12)$ \\
\hline Postfinancialization & $0.329(16.88)$ & $0.334(17.08)$ & $0.341(19.00)$ & $0.271(-7.32)$ \\
\hline \multicolumn{5}{|c|}{ Panel B: Volatility of comovement } \\
\hline Prefinancialization & 0.018 & 0.017 & 0.014 & 0.106 \\
\hline Financialization & $0.058(0.09)$ & $0.059(0.09)$ & $0.055(0.07)$ & $0.024(19.11)$ \\
\hline Postfinancialization & $0.099(0.03)$ & $0.097(0.03)$ & $0.092(0.02)$ & $0.103(1.06)$ \\
\hline \multicolumn{5}{|c|}{ Panel C: Correlation with realized comovement } \\
\hline Postfinancialization & 1.000 & 0.998 & 0.968 & -0.379 \\
\hline
\end{tabular}

Note: This table reports the summary statistics of the realized and model-implied commodity return comovement measure for the commodity factor model based on the first principal component extracted from the panel of 27 commodity returns. Panel A reports the average comovement, Panel B the standard deviation and Panel C the correlation of the comovement with the realized comovement. The first column reports the realized comovement, $C M{ }^{\text {real }}$, the second column reports the model-implied comovement, $C M^{\text {model }}$, the third column reports the comovement measure with fixed factor sensitivities, $C M^{\text {fixed } \beta}$, and the fourth column reports the comovement measure with fixed factor covariances, $C M^{\text {fixed } \Sigma}$. Statistics for a two-sample $t$-test ( $F$-test) between the prefinancialization period and the financialization or postfinancialization period are reported in parenthesis in Panel A (Panel B).

$$
\rho_{V, i j}(\tau)=\frac{\operatorname{Cov}_{\tau}\left(V_{i}, V_{j}\right)}{\sqrt{\operatorname{Var}_{\tau}\left(V_{i}\right) \operatorname{Var}_{\tau}\left(V_{j}\right)}},
$$

the correlation of the monthly volatilities of the return of commodity market $i$ and $j$ over a rolling window $\tau$ of 36 months.

Then, we can define the comovement measure of volatilities (CMV) analogously to returns as the weighted average of all correlation pairs:

$$
\operatorname{CMV}(\tau):=\sum_{i, j, i \neq j} w_{i j} \rho_{V, i j}(\tau)
$$

where $w_{i j}$ are weights such that $\sum_{i, j, i \neq j} w_{i j}=1$.

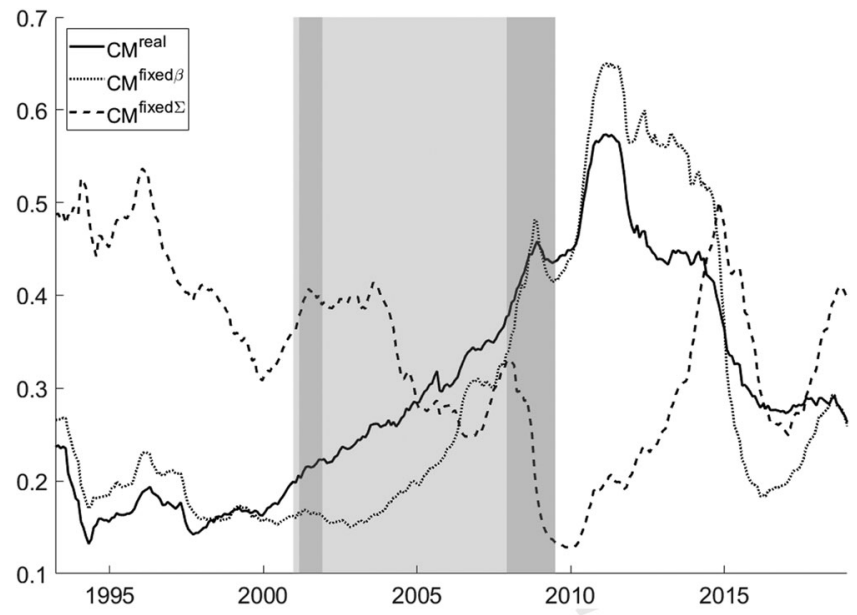

FIG URE 4 Comovement measure with fixed betas or factor covariances. This figure shows the realized commodity return comovement measure, $C M^{\text {real }}$, the comovement measure with fixed factor exposures, $C M^{\text {fixed } \beta}$, and the comovement measure with fixed factor variance, $C M^{\text {fixed } \Sigma}$, as defined in Equation (14). The correlations are adjusted for heteroskedasticity (Forbes \& Rigobon, 2002) and computed over a rolling window of 36 months. The light red shaded area marks the period of financialization from December 2000 to July 2008, dark shaded areas mark NBER recessions 
TABLE 7 Return and volatility comovements

\begin{tabular}{|c|c|c|c|c|}
\hline & \multicolumn{2}{|l|}{ Mean } & \multicolumn{2}{|l|}{$S D$} \\
\hline & $\mathbf{C M}$ & CMV & $\mathbf{C M}$ & CMV \\
\hline \multicolumn{5}{|c|}{ Panel A: Single commodity returns } \\
\hline Prefinacialization & 0.155 & 0.177 & 0.018 & 0.078 \\
\hline Financialization & $0.234(12.58)$ & $0.159(-1.97)$ & $0.058(0.09)$ & $0.042(3.56)$ \\
\hline \multicolumn{5}{|c|}{ Panel B: Commodity sector returns } \\
\hline $1990-2018$ & 0.130 & 0.200 & 0.108 & 0.230 \\
\hline Prefinacialization & 0.037 & 0.141 & 0.026 & 0.105 \\
\hline Financialization & $0.080(11.14)$ & $-0.038(-14.09)$ & $0.026(1.04)$ & $0.062(2.83)$ \\
\hline Postfinancialization & $0.234(19.45)$ & $0.416(13.79)$ & $0.095(0.08)$ & $0.171(0.38)$ \\
\hline
\end{tabular}

Note: This table reports the summary statistics of the CM and the CMV. Results in Panel A (Panel B) are based on the returns on 27 commodity markets (8 commodity sectors) as underlying assets. Statistics for a two-sample $t$-test ( $F$-test) between the prefinancialization period and the financialization or postfinancialization period are reported in parenthesis behind the respective figures.

Abbreviations: CM, commodity return comovements; CMV, commodity volatility comovements.

In Table 7, we present the mean and $S D$ of the comovement measure for returns $(C M)$ and volatilities $(C M V)$. In Panel A, we report the statistics as before using the returns or volatilities of the 27 commodities as underlying variables. In Panel B, we use the sector returns or volatilities as the underlying variables, eliminating the intrasectoral part of the comovement as those are aggregated within the sector return.

As for return comovements we find an increase in volatility comovements over the sample period confirming the results of Christoffersen et al. (2019). However, volatility comovements decrease during the financialization period from 0.177 to $0.159\left(t\right.$-stat $\left.{ }_{\Delta}=1.97\right)$, before they jump and more than double during the postfinancialization period to a significantly higher average of $0.477\left(t\right.$-stat $\left._{\Delta}=-21.84\right)$. The results for sector returns in Panel B show an even more significant decrease of comovements during the financialization period from 0.141 to $-0.038\left(t-\right.$ stat $\left._{\Delta}=14.09\right)$, before the sharp increase to 0.416 .

The graphs in Figure 5 emphasize the differences between the evolution of return and volatility comovements, with both having increased significantly after financialization. While the shift in commodity return comovements has been gradual over the financialization period, commodity volatility comovements have mainly been effected during the financial crisis jumping to higher regime.

These results reveal a clear differentiation between the gradual effects of financialization on the one hand, and the effect of the financial crisis on the other hand. One reason for the different behavior could be the relatively low volatility environment during the financialization period. While the structural interconnections have been built during

FI G URE 5 Commodity comovement measure for returns and volatilities. This figure shows the realized commodity return comovement measure, $C M^{\text {real }}$, and the realized commodity volatility comovement measure, $C M V^{\text {real }}$, as defined in Equation (16). The correlations are adjusted for heteroskedasticity (Forbes \& Rigobon, 2002) and computed over a rolling window of 36 months. The light red shaded area marks the period of financialization from December 2000 to July 2008, dark shaded areas mark NBER recessions

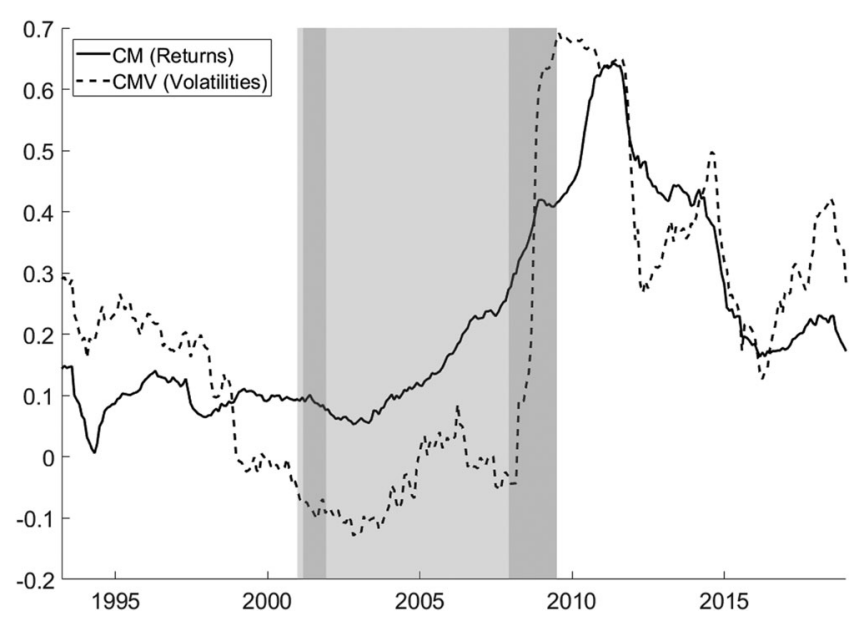


the financialization period, only the overlapping distress caused by the financial crisis and the bust of commodity markets (Singleton, 2014) brought the strong volatility comovements to light.

\section{5 | IMPLICATIONS}

\section{1 | Market integration and financialization}

Our results add to the discussion on market integration and financialization of commodity markets. We show that a one-factor model is able to explain most of the comovement within commodity markets leaving a negligible part of excess comovement. This is in contrast to the literature on excess comovement which usually finds larger parts of unexplained comovement.

Pindyck and Rotemberg (1990) define excess comovement as the comovement of returns that cannot be explained by the common effects of inflation, changes in aggregate demand, interest rates or exchange rates. Even after extending this set of variables to 184 macro variables (Le Pen \& Sévi, 2017), these models leave a significant amount of excess comovement.

Since we are able to capture the entire comovement with our parsimonious one-factor model, we can analyze which part of the model is contributing the most to the time variation and therefore the increase in comovements during the financialization period. This sheds light on whether the change is persistent or not. We find that it is mostly the variance of the factor that introduces the time variation into comovements. As the factor variance is more affected by short-term changes than the factor sensitivity, which relates factor returns to the commodity returns, this is evidence that the effects of financialization are less strong in the long term.

However, that financialization has affected commodity markets as a whole is evident from the dissection of intraand inter-sectoral comovements. We document a significant increase in the intra- and inter-sectoral comovements. This result supports the argument that index investment in commodity markets has increased the correlation between seemingly unrelated commodity markets through financial channels.

Table 8 reports the results of regressing the comovement on measures of trading activity and confirms the strong linkage between commodity comovements and trading activity. ${ }^{19}$ Speculative pressure can explain up to $21 \%$ (21\%) of the return (volatility) comovement. The positive relationship shows that higher trading activity indicates higher comovement of returns as well as volatilities.

However, we have also shown that return comovements and volatility comovements are affected differently by financialization. While both have increased significantly post financialization, the channels are arguably different. The gradual increase of commodity return comovements during the financialization is not matched in volatility comovements. Instead volatilities even comove less during the financialization period, before they jump significantly during the financial crisis. This observation is interesting as it motivates a discussion of the distinct effects of financialization and the financial crisis on commodity markets.

\section{2 | Risk management}

For risk managers the covariance and hence comovements are crucial inputs as they determine the riskiness of a portfolio. We therefore look into the effect of the comovement on the VaR, a common risk measure, which we compute for a portfolio $P$ as

$$
\operatorname{VaR}_{\alpha}(P):=\text { Notional } \cdot \Phi^{-1}(1-\alpha) \cdot \sigma_{P}
$$

where $1-\alpha$ is the confidence level, the notional amount is set to $\$ 1,000,000, \Phi^{-1}$ is the inverse standard normal distribution function and $\sigma_{P}$ is the portfolio's monthly volatility. The covariance of commodity returns enters the VaR through the volatility of the portfolio, since

\footnotetext{
${ }^{19}$ We proxy trading activity with speculative pressure, computed as the fraction of long minus short positions over the total open interest of noncommercial traders from the Commitment of Traders (CoT) Report issued by the CFTC, see also Fan et al. (2020). The market-wide speculative pressure is calculated as the average speculative pressure across all markets.
} 
TABLE 8 Comovement and trading activity

\begin{tabular}{|c|c|c|}
\hline & Return comovement & Volatility comovement \\
\hline \multirow[t]{2}{*}{ Intercept } & 0.0308 & 0.1248 \\
\hline & $(2.13)$ & $(5.55)$ \\
\hline SP & $(4.93)$ & $(6.75)$ \\
\hline$R^{2}$ & 0.21 & 0.21 \\
\hline
\end{tabular}

Note: This table reports the results of regressions of the comovement measure for returns and the comovement measure for volatilities on a constant and speculative pressure (SP). For each commodity market speculative pressure is computed as the fraction of long minus short positions over the total open interest of noncommercial traders from the Commitment of Traders Report of the CFTC. The variable SP is defined as the average speculative pressure over all 27 commodity markets at each point in time. Standard errors are corrected according to Newey and West (1987) with two lags and respective $t$-statistics are reported in parenthesis.

$$
\sigma_{P}^{2}=\operatorname{Var}\left(\sum_{i=1}^{N} w_{i} R_{i}\right)=\sum_{i=1}^{N} w_{i}^{2} \operatorname{Var}\left(R_{i}\right)+\sum_{j \neq i} w_{i} w_{j} \operatorname{Cov}\left(R_{i}, R_{j}\right)
$$

where $w_{i}$ are weights such that $\sum_{i=1}^{N} w_{i}=1$. Hence, changes in the covariance structure will affect the VaR. Anderson (2017) uses the VaR to study the economic impact of changes in the covariance of credit default swaps. In a similar fashion, we analyze the change of VaR using different models to capture the comovement of commodity futures returns. For a rolling window $\tau$ of 36 months, we denote

$$
\begin{aligned}
& \operatorname{Cov}^{\text {real }}(\tau)=\operatorname{Cov}_{\tau}\left(R_{i}, R_{j}\right), \quad \operatorname{Cov}^{\text {model }}(\tau)=\beta^{\prime} \Sigma_{F, \tau} \beta_{j \tau}, \\
& \operatorname{Cov}^{\text {fixed } \beta}(\tau)=\overline{\beta_{i}} \Sigma_{F, \tau} \overline{\beta_{j}} \quad \operatorname{Cov}^{\text {fixed } \Sigma}(\tau)=\beta^{\prime} \overline{\Sigma_{F}} \beta_{j \tau},
\end{aligned}
$$

as the realized covariance, the model-implied covariance, the estimated covariance with fixed betas and the estimated covariance with fixed factor covariances, where $\beta_{i \tau}$ and $\beta_{j \tau}$ are the coefficients from the time-series regression and $\Sigma_{F, \tau}$ is the covariance of the factors. Again, $\overline{\beta_{i}}$, $\overline{\beta_{j}}$, and $\overline{\Sigma_{F}}$ denote the time-series averages. ${ }^{20}$

In Table 9 we compare the VaR before, during, and after financialization to see whether the model-implied covariance estimates are able to capture the changes in the VaR. The first column shows the VaR using the covariance of the realized returns, $\mathrm{Cov}^{\text {real }}$, for the computation. In the second column, we use the model-implied covariance $\mathrm{Cov}^{\text {model }}$. We find that the model-implied covariance gives a good estimate of the realized VaR, capturing the increasing risk during and after financialization.

In the third column of Table 9, we compute VaR with fixed factor sensitivity. We can see that these VaR estimates are reasonably close to the realized and model-implied estimates. They are especially able to capture the increased risk postfinancialization. The VaR based on covariances with fixed factor variance is presented in the fourth column of Table 9 and cannot capture this change of risk. For example, the 5\% VaR is rather stable from $\$ 12,119$ per $\$ 1,000,000$ before financialization to $\$ 12,492$ per $\$ 1,000,000$ during financialization and $\$ 12,491$ per $\$ 1,000,000$ after financialization. We find a similar pattern for the $1 \%$ VaR in Panel B of Table 9.

This result points out the importance of the variation in the factor variance for the comovements. It is crucial for investors to capture these time-variations to be able to assess the risks of a commodity portfolio correctly. For a risk manager who is facing the decision to allocate limited resources to computation and maintenance of risk metrics, this result emphasizes the importance of the factor variance for the VaR. As VaR is an important metric for financial regulation, an inaccurate estimation can have important consequences. Hence, we recommend focusing the attention on the variation in factor variance rather than beta.

\footnotetext{
${ }^{20}$ As mentioned earlier, for a single factor model the factor covariance matrix is a scalar.
} 
TA B LE 9 Value-at-risk for estimated covariances

\begin{tabular}{|c|c|c|c|c|}
\hline & Cov $v^{\text {real }}$ & Cov ${ }^{\text {model }}$ & $\operatorname{Cov} v^{\text {fixed } \beta}$ & $\operatorname{Cov} v^{\text {fixed } \Sigma}$ \\
\hline 1990-2018 & $\$ 12,672$ & $\$ 12,822$ & $\$ 12,514$ & $\$ 12,495$ \\
\hline Financialization & $\$ 12,038$ & $\$ 12,050$ & $\$ 12,078$ & $\$ 12,492$ \\
\hline Postfinancialization & $\$ 15,361$ & $\$ 15,341$ & $\$ 15,369$ & $\$ 12,491$ \\
\hline 1990-2018 & $\$ 17,922$ & $\$ 18,135$ & $\$ 17,698$ & $\$ 17,672$ \\
\hline Prefinancialization & $\$ 11,423$ & $\$ 11,833$ & $\$ 11,972$ & $\$ 17,140$ \\
\hline Financialization & $\$ 17,026$ & $\$ 17,043$ & $\$ 17,082$ & $\$ 17,668$ \\
\hline Postfinancialization & $\$ 21,725$ & $\$ 21,696$ & $\$ 21,737$ & $\$ 17,667$ \\
\hline
\end{tabular}

Note: This table reports the Value-at-Risk (VaR) for a commodity portfolio using different covariance matrices for the computation of the volatility. The VaR for a portfolio $P$ is computed as in Equation (17).

$$
\operatorname{VaR}_{\alpha}(P):=\operatorname{Notional} \cdot \Phi^{-1}(1-\alpha) \cdot \sigma_{P}
$$

where $1-\alpha$ is the confidence level, the notional is $\$ 1,000,000, \Phi^{-1}$ is the inverse normal distribution function and $\sigma_{P}$ is the $S D$ of portfolio returns $R_{P}$. The portfolio's volatility is based on the different covariance matrices in Equation (19)

$$
\begin{array}{ll}
\operatorname{Cov}^{\text {real }}(\tau)=\operatorname{Cov}_{\tau}\left(R_{i}, R_{j}\right), & \operatorname{Cov}^{\text {model }}(\tau)=\beta^{\prime} \Sigma_{F, \tau} \beta_{j \tau}, \\
\operatorname{Cov}^{\text {fixed } \beta}(\tau)={\overline{\beta_{i}}}^{\prime} \Sigma_{F, \tau} \overline{\beta_{j}} & \operatorname{Cov}^{\text {fixed } \Sigma}(\tau)=\beta^{\prime} \overline{\Sigma_{F}} \beta_{j \tau},
\end{array}
$$

where $\operatorname{Cov}^{\text {real }}(\tau)$ is the realized covariance over the rolling window $\tau$ of 36 months, $\operatorname{Cov}^{\text {model }}(\tau)$ is the model-implied covariance using the estimated returns from the time-series regression, $\operatorname{Cov}^{\text {fixed } \beta}(\tau)$ is the covariance with constant betas, and $\operatorname{Cov}^{\text {fixed } \Sigma}(\tau)$ is the covariance with constant factor covariances. Panel A shows the VaR for $\alpha=5 \%$ and Panel B for $\alpha=1 \%$.

\section{I ROBUSTNESS CHECKS}

We run several robustness checks and discuss the results in this section. The tabulated results are presented in the online appendix.

\section{1 | Model settings}

To start with, we want to make sure that the performance of the model is not sensitive to our regression design. Therefore, we repeat the analysis of Section 3 after (i) changing the size of the rolling window to 24 months and 60 months, (ii) omitting the adjustment for heteroskedasticity, and (iii) changing the computation of $V^{2} r_{\text {short }}$ in Equation (7) to be the 12- or 6-month variance.

Tables A.3 and A.4 of the online appendix show that these alternative specifications do not change the general result that the commodity factor model with re-estimated betas is the best model to explain the comovement of commodity futures returns.

\section{2 | Sample choice}

There are several reasons, why we decided to concentrate our analysis on the set of 27 commodities over the sample period from 1990 to 2018. First, the availability of certain variables restricts our sample choice. The macro variables used in the model of Le Pen and Sévi (2017) for emerging markets are largely unavailable before 1990, as is volume data to compute market weights. Second, the composition of the entire commodity market changes over time. Starting with only agricultural commodities in 1959, metals are introduced in the 1970s, and energy commodities become tradable in the 1980s. The introduction of new commodity markets makes a comparison through time very difficult. With respect 
to the commodity markets chosen, the portfolio of 27 markets is the broadest representation of the different sectors and commodities, allowing us to get a broad view of all interactions.

However, to address any concerns about our results being dependent on the sample choice, we repeat the analysis with the smaller set of 21 commodities studied by Szymanowska et al. (2014) for the period from 1990 to 2018 (Table A.5 of the online appendix, Panel A). To rule out that results are driven by the effect of a certain sector, we also repeat the analysis each time excluding all commodities of one of the six sectors (Table A.5 of the online appendix, Panel B). Results remain qualitatively similar.

\section{3 | Alternative comovement measures}

One concern is that our model comparison might be biased by the way we measure comovements. Although Forbes and Rigobon (2002) state that using correlation coefficients is the most straight forward framework, part of the literature has studied commodity comovements methodologically using Vector Autoregressive models for the return volatility as in Diebold et al. (2017) or assessing the excess comovement, that is, the comovement of the error term $\epsilon$ in Equation (3), with a GARCH framework as Ohashi and Okimoto (2016). We favor a simple factor model as we are interested in the explainable part of the commodity future returns. We look at the pairwise correlations as they appear to be at the heart of the financialization debate (Bhardwaj et al., 2015).

However, the high explanatory power of the global factor for the comovement measure raises the concern that the result might be mechanical. Let us illustrate this with a simple example. Consider a simple one-factor model based on an equally-weighted market factor, that is,

$$
R_{i}=\alpha_{i}+\beta_{i} R^{\mathrm{MRKT}}+\epsilon_{i} \Rightarrow \operatorname{Cov}\left(R_{i}, R_{j}\right)=\beta_{i} \beta_{j} \operatorname{Var}\left(R^{\mathrm{MRKT}}\right)+\operatorname{Cov}\left(\epsilon_{i}, \epsilon_{j}\right)
$$

with $\alpha_{i}, \beta_{i}$ and $\epsilon_{i}$ as intercept, slope and residual, respectively. Recall that since the market factor here is an equallyweighted average of all constituents, the average exposure to this factor $(\beta)$ must equal one and hence the average of all possible products of $\beta_{i}$ and $\beta_{j}$ as well, that is,

$$
\frac{1}{N} \sum_{i=1}^{N} \beta_{i}=1 \quad \Rightarrow \quad \frac{1}{N^{2}} \sum_{i, j=1}^{N} \beta_{i} \beta_{j}=\left(\frac{1}{N} \sum_{i=1}^{N} \beta_{i}\right) \cdot\left(\frac{1}{N} \sum_{j=1}^{N} \beta_{j}\right)=1 .
$$

If we additionally assume the comovement measure to be equally-weighted, that is, $w_{i j}=\frac{1}{N^{2}}$ for a number of $N$ commodity markets, and we average over all covariances including the variances on the diagonal, then

$$
\begin{aligned}
\sum_{i, j=1}^{N} w_{i j} \operatorname{Cov}\left(R_{i}, R_{j}\right) & \stackrel{(20)}{=} \sum_{i, j=1}^{N} \frac{1}{N^{2}}\left(\beta_{i} \beta_{j} \operatorname{Var}\left(R^{\mathrm{MRKT}}\right)+\operatorname{Cov}\left(\epsilon_{i}, \epsilon_{j}\right)\right) \\
& =\operatorname{Var}\left(R^{\mathrm{MRKT}}\right) \frac{1}{N^{2}} \sum_{i, j=1}^{N} \beta_{i} \beta_{j}+\frac{1}{N^{2}} \sum_{i, j=1}^{N} \operatorname{Cov}\left(\epsilon_{i}, \epsilon_{j}\right) \\
& \stackrel{(21)}{=} \operatorname{Var}\left(R^{\mathrm{MRKT}}\right)+\frac{1}{N^{2}} \sum_{i, j=1}^{N} \operatorname{Cov}\left(\epsilon_{i}, \epsilon_{j}\right) .
\end{aligned}
$$

Because in this case, the market variance, $\operatorname{Var}\left(R^{\mathrm{MRKT}}\right)$, is equal to the comovement measure, we obtain zero average residual covariance, that is,

$$
\operatorname{Var}\left(R^{\mathrm{MRKT}}\right)=\sum_{i, j=1}^{N} \frac{1}{N^{2}} \operatorname{Cov}\left(R_{i}, R_{j}\right) \Rightarrow \frac{1}{N^{2}} \sum_{i, j=1}^{N} \operatorname{Cov}\left(\epsilon_{i}, \epsilon_{j}\right)=0 .
$$

There are three reasons, we think our results are not driven by this tautology. First, the comovement measure we use differs from the simplified example above as we do not consider the diagonal elements, that is, the variances, and we do not equally weight the covariances. More specifically we do not use the same weights for the global factor and the comovement measure. Second, since we apply the adjustment for heteroskedasticity by Forbes and Rigobon (2002) 
the equations for covariances do not hold for correlations. Third, we conduct the following robustness check to show that our results are not driven by the described averaging effect. Define the partial comovement measure

$$
\mathrm{CM}_{i}^{\text {real }}(\tau)=\sum_{j \neq i} w_{j}\left(\rho_{i j}^{\text {real }}(\tau)^{*}+\rho_{j i}^{\text {real }}(\tau)^{*}\right)
$$

where $\rho_{i j}^{\text {real }}(\tau)^{*}$ is the heteroskedasticity-adjusted correlation coefficient between commodity return $i$ and $j$ during the period $\tau$ and $\sum_{j \neq i} w_{j}=1$. Analogous to (8), we define the model-implied partial comovement measure $\mathrm{CM}_{i}^{\text {model }}$.

Table A.6 of the online appendix reports the MAE and RMSE for the partial commodity measure. Although the averaging effect is visible, it does not drive the results. We find an average MAE (RMSE) of 0.0474 (0.0532) over the 27 partial commodity comovements, while it is $0.0302(0.0345)$ for the cumulated measure including all commodity pairs (see Table A.6 of the online appendix).

\section{7 | CONCLUSION}

This paper examines the comovements of commodity futures returns and volatilities. We start by showing that a onefactor model is able to explain a large proportion of the realized comovements. Importantly, this result suggests that there is very little evidence of excess comovements.

We confirm previous evidence of increased comovement during and after financialization and pin its source down to the intersectoral comovements. Dissecting the evidence further, we show that changes in factor exposure play a minor role for changes of comovements. This result poses a challenge to the literature on the integration of commodity markets. The increase of return comovements during financialization is mainly driven by a temporary increase in factor variance casting doubt on commodity markets becoming more integrated in the long run. Lastly, we find increased comovement of volatilities following the financial crisis, suggesting the need for a discussion of the distinct effects of financialization and the financial crisis on commodity comovements.

\section{ACKNOWLEDGMENTS}

We are thankful for constructive comments of an anonymous referee, as well as the participants of the Commodity and Energy Markets Annual Meeting at Sapienza University in Rome, the International Finance and Banking Society Conference in Porto, and the Annual Meeting of the German Finance Association in Trier. Contact: prokopczuk@fcm.uni-hannover.de (M. Prokopczuk), c.wese-simen@liverpool.ac.uk (C. Wese Simen), and r.c.wichmann@pgr.icmacentre.ac.uk (R. Wichmann).

\section{DATA AVAilaBiLity STATEMENT}

The data that support the findings of this study are available from the corresponding author upon reasonable request.

\section{ORCID}

Marcel Prokopczuk (D) http://orcid.org/0000-0003-4886-2729

Robert Wichmann (i) http://orcid.org/0000-0001-8895-4404

\section{REFERENCES}

Adhikari, R., \& Putnam, K. J. (2020). Comovement in the commodity futures markets: An analysis of the energy, grains, and livestock sectors. Journal of Commodity Markets, 18, 100090.

Alquist, R., Bhattarai, S., \& Coibion, O. (2020). Commodity-price comovement and global economic activity. Journal of Monetary Economics, $112,41-56$.

Anderson, M. (2017). What drives the commonality between credit default swap spread changes? Journal of Financial and Quantitative Analysis, 52(1), 243-275.

Bakshi, G., Gao, X., \& Rossi, A. (2019). Understanding the sources of risk underlying the cross section of commodity returns. Management Science, 65(2), 619-641.

Bekaert, G., Hodrick, R. J., \& Zhang, X. (2009). International stock return comovements. Journal of Finance, 64(6), $2591-2626$.

Berben, R.-P., \& Jansen, W. J. (2005). Comovement in international equity markets: A sectoral view. Journal of International Money and Finance, 24(5), 832-857.

Bhardwaj, G., Gorton, G., \& Rouwenhorst, G. (2015). Facts and fantasies about commodity futures ten years later (NBER Working Paper Series No. 21243). 
Bhardwaj, G., Gorton, G. B., \& Rouwenhorst, K. G. (2014). Fooling some of the people all of the time: The inefficient performance and persistence of commodity trading advisors. Review of Financial Studies, 27(11), 3099-3132.

Bloomberg. (2019). Commodity Futures; Bloomberg; Identifiers see Table A.1 of the Online Appendix.

Boons, M., \& Prado, M. P. (2019). Basis-momentum. Journal of Finance, 74(1), 239-279.

Cheng, I.-H., \& Xiong, W. (2014). Financialization of commodity markets. Annual Review of Financial Economics, 6(1), 419-441.

Christoffersen, P., Lunde, A., \& Olesen, K. V. (2019). Factor structure in commodity futures return and volatility. Journal of Financial and Quantitative Analysis, 54(3), 1083-1115.

Commodity Futures Trading Comission. (2019). Commitment of Traders Report. https://www.cftc.gov/MarketReports/CommitmentsofTraders/index.htm

Dahl, R. E., Oglend, A., \& Yahya, M. (2020). Dynamics of volatility spillover in commodity markets: Linking crude oil to agriculture. Journal of Commodity Markets, 20, 100111.

DataStream. (2019). Macro Variables; Bloomberg; Identifiers see Table A.2, Panel B, of the Online Appendix.

Deb, P., Trivedi, P. K., \& Varangis, P. (1996). The excess co-movement of commodity prices reconsidered. Journal of Applied Econometrics, 11(3), 275-291.

DelleChiaie, S., Ferrara, L., \& Giannone, D. (2017). Common factors of commodity prices (ECB Working Paper No. 2112).

Diebold, F. X., Liu, L., \& Yilmaz, K. (2017). Commodity connectedness (NBER Working Paper No. 23685).

Fan, J. H., Fernandez-Perez, A., Fuertes, A.-M., \& Miffre, J. (2020). Speculative pressure. Journal of Futures Markets, 40(4), $575-597$.

Fattouh, B., Kilian, L., \& Mahadeva, L. (2013). The role of speculation in oil markets: What have we learned so far? Energy Journal, 34(3), 7-34.

Federal Reserve Bank of St. Louis. (2019). Financial Variables; Federal Reserve Economic Data; Identifiers see Table A.2, Panel A, of the Online Appendix. https://fred.stlouisfed.org/

Forbes, K. J., \& Rigobon, R. (2002). No contagion, only interdependence: Measuring stock market comovements. Journal of Finance, 57(5), 2223-2261.

Henderson, B. J., Pearson, N. D., \& Wang, L. (2015). New evidence on the financialization of commodity markets. Review of Financial Studies, 28(5), 1285-1311.

Irwin, S. H., \& Sanders, D. R. (2012). Testing the Masters hypothesis in commodity futures markets. Energy Economics, 34(1), 256-269.

Le Pen, Y., \& Sévi, B. (2017). Futures trading and the excess co-movement of commodity prices. Review of Finance, 22(1), 381-418.

Main, S., Irwin, S. H., Sanders, D. R., \& Smith, A. (2018). Financialization and the returns to commodity investments. Journal of Commodity Markets, 10, 22-28.

Newey, W. K., \& West, K. D. (1987). Hypothesis testing with efficient method of moments estimation. International Economic Review, 28(3), 777-787.

Ohashi, K., \& Okimoto, T. (2016). Increasing trends in the excess comovement of commodity prices. Journal of Commodity Markets, 1(1), 48-64.

Pindyck, R. S., \& Rotemberg, J. J. (1990). The excess co-movement of commodity prices. Economic Journal, 100(403), 1173-1189.

Prokopczuk, M., Symeonidis, L., \& Wese Simen, C. (2017). Variance risk in commodity markets. Journal of Banking \& Finance, 81, $136-149$.

Silvennoinen, A., \& Thorp, S. (2013). Financialization, crisis and commodity correlation dynamics. Journal of International Financial Markets, Institutions and Money, 24(C), 42-65.

Singleton, K. J. (2014). Investor flows and the 2008 boom/bust in oil prices. Management Science, 60(2), $300-318$.

Szymanowska, M., Roon, F., Nijman, T., \& Goorbergh, R. (2014). An anatomy of commodity futures risk premia. Journal of Finance, 69(1), 453-482.

Tang, K., \& Xiong, W. (2012). Index investment and the financialization of commodities. Financial Analysts Journal, 68(6), 54-74.

\section{SUPPORTING INFORMATION}

Additional Supporting Information may be found online in the supporting information tab for this article.

How to cite this article: Prokopczuk, M., Wese Simen, C., \& Wichmann, R. (2021). The dynamics of commodity return comovements. Journal of Futures Markets, 1-21. https://doi.org/10.1002/fut.22222 